\title{
Spectrophotometric Determination of Zolmitriptan in Bulk Drug and Pharmaceuticals Using Vanillin as a Reagent
}

\author{
Kudige N. Prashanth, Kanakapura Basavaiah, and Madihalli S. Raghu \\ Department of Chemistry, University of Mysore, Manasagangotri, Mysore, Karnataka 570006, India \\ Correspondence should be addressed to Kanakapura Basavaiah; basavaiahk@yahoo.co.in
}

Received 25 February 2013; Accepted 25 March 2013

Academic Editors: T. Macko and A. Przyjazny

Copyright ( 2013 Kudige N. Prashanth et al. This is an open access article distributed under the Creative Commons Attribution License, which permits unrestricted use, distribution, and reproduction in any medium, provided the original work is properly cited.

\begin{abstract}
An accurate and precise spectrophotometric method is presented for the determination of zolmitriptan (ZMT) based on the formation of a red color product with vanillin in presence of concentrated $\mathrm{H}_{2} \mathrm{SO}_{4}$, with the chromogen being measured at $580 \mathrm{~nm}$. The reaction proceeds quantitatively at room temperature in $10 \mathrm{~min}$. The calibration curve is linear over the range $5.0-90.0 \mu \mathrm{g} \mathrm{mL}$ and described by the regression equation $Y=(-) 0.0101+0.0117 X$ with a regression coefficient $(r)$ of $0.9994(n=7)$. The calculated molar absorptivity and Sandell sensitivity values are $3.3 \times 10^{3} \mathrm{~L} \mathrm{~mol}^{-1} \mathrm{~cm}^{-1}$ and $0.0872 \mu \mathrm{g} \mathrm{cm}^{-2}$, respectively. The limits of detection (LOD) and quantification (LOQ) calculated as per ICH guidelines are 1.26 and $3.81 \mu \mathrm{g} \mathrm{mL}^{-1}$, respectively. The within-day accuracy expressed as relative error was better than $1.78 \%$ with precision (RSD) ranging from 0.83 to $1.45 \%$. The between-day accuracy ranged from 1.21 to $1.84 \%$ with a precision less than $1.66 \%$. The method was successfully applied to the analysis of one brand of tablet containing zolmitriptan. The results obtained were in agreement with those obtained by published reference method. The accuracy was also checked by placebo blank and synthetic mixture analyses besides recovery study via standard addition procedure.
\end{abstract}

\section{Introduction}

The antimigraine drug zolmitriptan (Figure 1) is a selective agonist of serotonin (5-hydroxytryptamine; 5-HT) type $1 \mathrm{~B}$ and $1 \mathrm{D}$ receptors and chemically known as (4S)4-[[3-[2-(dimethylamino) ethyl]-1H-indol-5-yl] methyl]-2oxazolidinone. Zolmitriptan (ZMT) binds with high affinity to human $5-\mathrm{HT}_{1 \mathrm{~B}}$ and $5-\mathrm{HT}_{1 \mathrm{D}}$ receptors leading to cranial blood vessel constriction. The therapeutic activity of ZMT for the treatment of migraine headache can most likely be attributed to the agonist effects at the $5 \mathrm{HT}_{1 \mathrm{~B} / 1 \mathrm{D}}$ receptors on intracranial blood vessels (including the arteriovenous anastomoses) and sensory nerves of the trigeminal system, which result in cranial vessel constriction and inhibition of proinflammatory neuropeptide release [1].

ZMT is not included in any pharmacopeia. Literature survey reveals that few analytical methods have been published for analysis of ZMT in human plasma and include highperformance liquid chromatography (HPLC) with coulometric [2], mass spectrometric detection [3-5], and liquid chromatography-mass spectrometry $[1,6,7]$.
High-performance liquid chromatography (HPLC) with UV-detection has been widely used for the quantitative determination of ZMT in pharmaceuticals [8-15]. Ultraperformance liquid chromatography (UPLC) [16], liquid chromatography-mass spectrometry [17], voltammetry [18], and UV-spectrophotometry methods [19-21] are the other techniques applied for the assay of ZMT in pharmaceuticals.

Only three visible spectrophotometric methods have been reported for the assay of ZMT in pharmaceuticals. The first method reported by Raza et al. [22] is based on the charge-transfer reaction of ZMT with 2,3-dichloro-5,6dicyano-1,4-benzoquinone in acetonitrile medium to form a colored product. The other two methods reported by Aydogmus and Inanli [23] are based on the formation of yellow ion-pair complexes between ZMT and tropaeolin OO (TPOO) and bromothymol blue (BTB), which were extracted into chloroform and measured at 411.5 and $410 \mathrm{~nm}$, respectively.

Most of the reported methods [8-21] require expensive instrumental setup, expertise personnel, and complicated procedure. Two of the reported visible spectrophotometric 


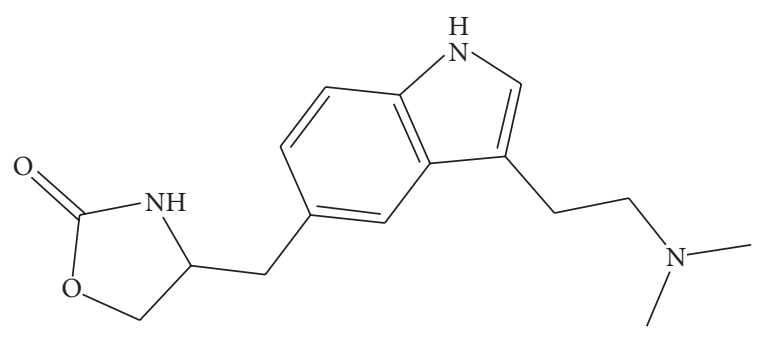

FIgURE 1: Structure of ZMT.

methods [23] require liquid-liquid extraction and strict $\mathrm{pH}$ control. The aim of the present work is to develop simple, sensitive and cost-effective spectrophotometric method for the determination of ZMT in pharmaceutical formulation. The method makes use of vanillin as the reagent in presence of concentrated $\mathrm{H}_{2} \mathrm{SO}_{4}$ and has been demonstrated to be superior to the existing spectrophotometric methods in terms of simplicity, speed, working conditions, and accuracy and precision.

\section{Materials and Methods}

2.1. Apparatus. A Systronics model 106 digital spectrophotometer provided with $1 \mathrm{~cm}$ matched quartz cells was used for absorbance measurements.

2.2. Reagents and Materials. All chemicals were of analytical reagent grade, and distilled water was used to prepare solutions.

Vanillin (4\%). The solution was prepared by dissolving $4 \mathrm{~g}$ of vanillin (Loba Chemie, Mumbai, India) in $100 \mathrm{~mL}$ methanol (Merck Ltd., Mumbai, India).

Sulphuric Acid. Concentrated $\mathrm{H}_{2} \mathrm{SO}_{4}$ (Merck, Mumbai, India; sp. gr. 1.84) was used as such.

Standard Drug Solution. Pharmaceutical grade ZMT (99.80\% pure) was kindly provided by Jubilant life Sciences, Mysore, India, and was used as received. A stock standard solution equivalent to $200 \mu \mathrm{g} \mathrm{mL}^{-1}$ ZMT was prepared by dissolving $50 \mathrm{mg}$ of pure drug in methanol and diluting to $250 \mathrm{~mL}$ in calibrated flask with the same solvent.

\subsection{Construction of Calibration Curves}

2.3.1. General Procedure. Different aliquots $(0.25,0.5,1.0$, $\ldots, 4.5 \mathrm{~mL}$ ) of $200 \mu \mathrm{g} \mathrm{mL}^{-1}$ ZMT solution were accurately measured and transferred into a series of $10 \mathrm{~mL}$ volumetric flasks, and the total volume was brought to $4.5 \mathrm{~mL}$ with methanol. To each flask $1 \mathrm{~mL}$ of $4 \%$ vanillin was added followed by $1 \mathrm{~mL}$ of concentrated $\mathrm{H}_{2} \mathrm{SO}_{4}$ and kept aside for 10 minutes; finally the volume was brought up to mark with methanol. The absorbance was measured at $580 \mathrm{~nm}$ versus reagent blank. A calibration graph was prepared by plotting the measured absorbance versus concentration. The concentration of the unknown was read from the calibration graph or computed from the regression equation derived using the Beer's law data.

2.3.2. Procedure for Tablets. Twenty tablets were weighed and pulverized into a fine powder. An amount of tablet powder equivalent to $20 \mathrm{mg}$ of ZMT was weighed into a $100 \mathrm{~mL}$ calibrated flask, $40 \mathrm{~mL}$ of methanol added, and the mixture shaken for $20 \mathrm{~min}$; then the volume was made up to the mark with the same solvent, mixed well and filtered using Whatman no. 42 filter paper. The filtrate equivalent to $200 \mu \mathrm{g} \mathrm{mL}^{-1}$ was subjected to analysis using the procedure described previously.

2.3.3. Procedure for the Analysis of Placebo Blank and Synthetic Mixture. A placebo blank containing starch $(50 \mathrm{mg})$, acacia (45 mg), hydroxyl cellulose $(60 \mathrm{mg})$, sodium citrate $(70 \mathrm{mg})$, lactose $(20 \mathrm{mg})$, talc $(60 \mathrm{mg})$, magnesium stearate $(55 \mathrm{mg})$, and sodium alginate $(60 \mathrm{mg})$ was prepared, and $10 \mathrm{mg}$ of the placebo blank was extracted with $5 \mathrm{~mL}$ methanol, and the solution was made as described under "procedure for tablets" and then subjected to analysis.

A synthetic mixture was prepared by adding $20 \mathrm{mg}$ of ZMT to about $20 \mathrm{mg}$ of the placebo blank prepared previosly homogenized, and the solution was prepared as done under "procedure for tablets." The filtrate was collected in a $100 \mathrm{~mL}$ flask. The synthetic mixture solution was subjected to analysis by using the previous procedure.

\section{Results and Discussion}

3.1. Chemistry. Enamines are formed by a condensation reaction between a secondary amine and an aldehyde or ketone in the presence of an acid catalyst $[24,25]$. The formation of enamine forms the basis for the spectrophotometric determination of compounds of pharmaceutical significance. Vanillin, an aromatic aldehyde, has been applied to the quantification of drugs with primary or secondary amine in acidic medium using spectrophotometry [26]. The proposed method is based on the formation of chromogenic enamine between the secondary amino group of ZMT and aldehyde group of vanillin. The most probable condensation step for the formation of enamine between ZMT and vanillin is presented in Scheme 1.

3.2. Spectral Characteristics. The absorption spectrum of the chromogen formed between ZMT and vanillin was recorded between 400 to $760 \mathrm{~nm}$ against respective reagent blank and the same is shown in Figure 2. The red-colored enamine exhibits $\lambda_{\max }$ at $580 \mathrm{~nm}$. The reagent blank showed negligible absorbance at $580 \mathrm{~nm}$. The measurements were thus made at this wavelength.

3.3. Optimization of Experimental Variables. Various experimental variables were optimized to achieve maximum sensitivity.

3.3.1. Effect of Vanillin. Vanillin is insoluble in water and $\mathrm{H}_{2} \mathrm{SO}_{4}$. In methanol, both vanillin and ZMT were found 


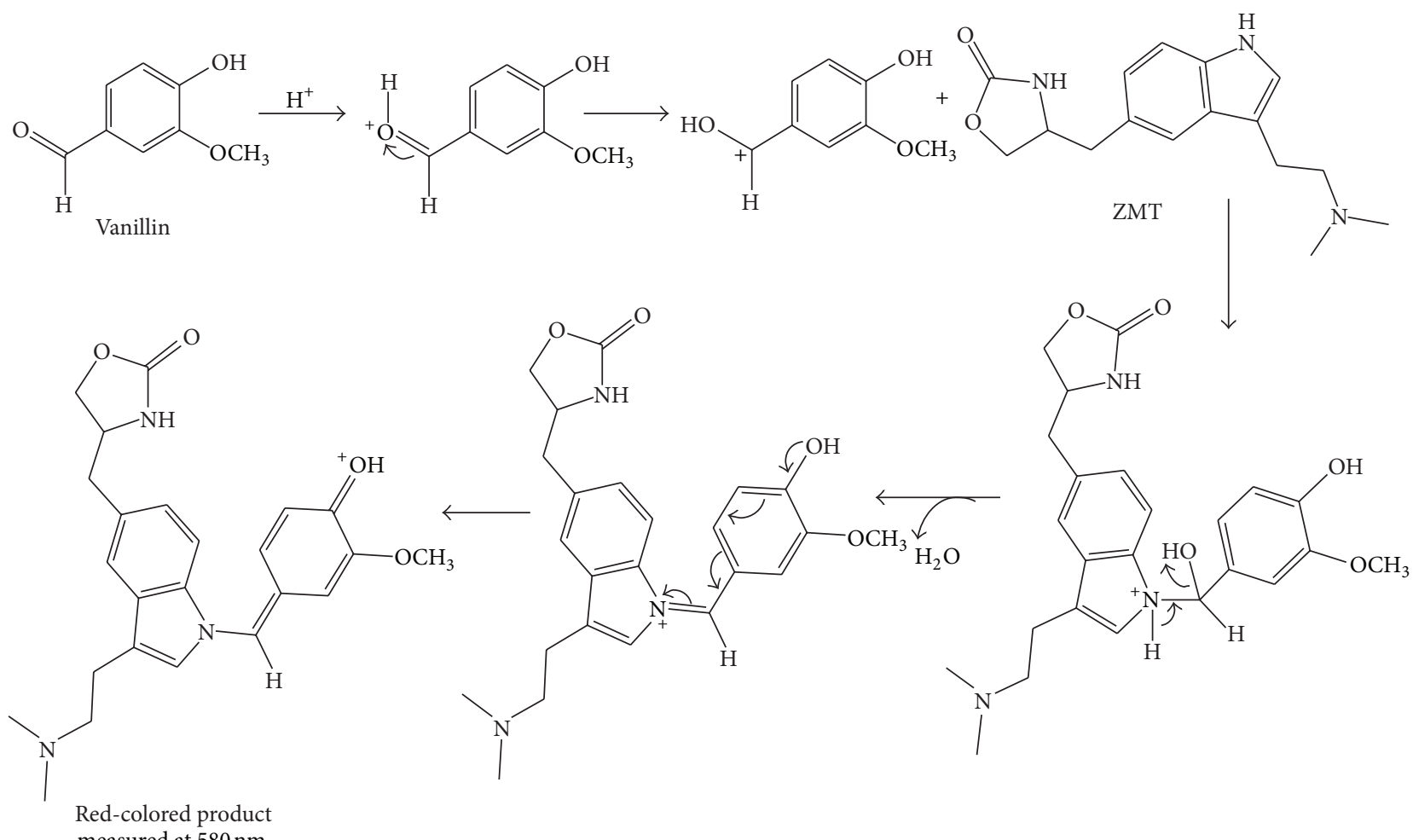

Scheme 1: The proposed reaction pathway for enamine formation.

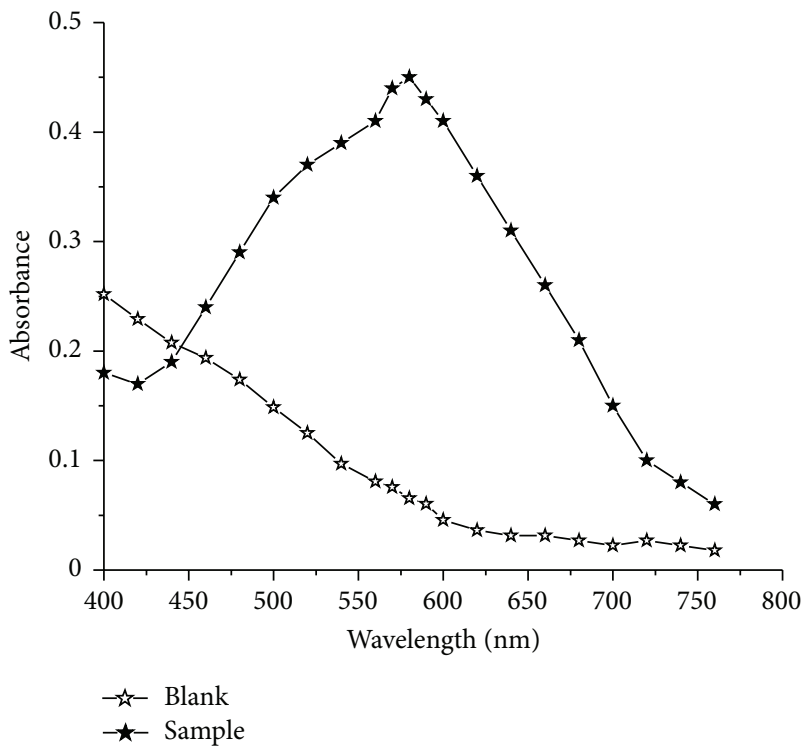

FIGURE 2: Absorption spectra of the colored product $\left(40 \mu \mathrm{g} \mathrm{mL}^{-1}\right.$ ZMT).

to dissolve, and the red-colored reaction product was also obtained in this medium. Hence, methanol was used to prepare vanillin and ZMT solutions. The effect of vanillin on the sensitivity of the reaction was studied by using $4 \%$ vanillin, and it was observed that when $0.5-2 \mathrm{~mL}$ was

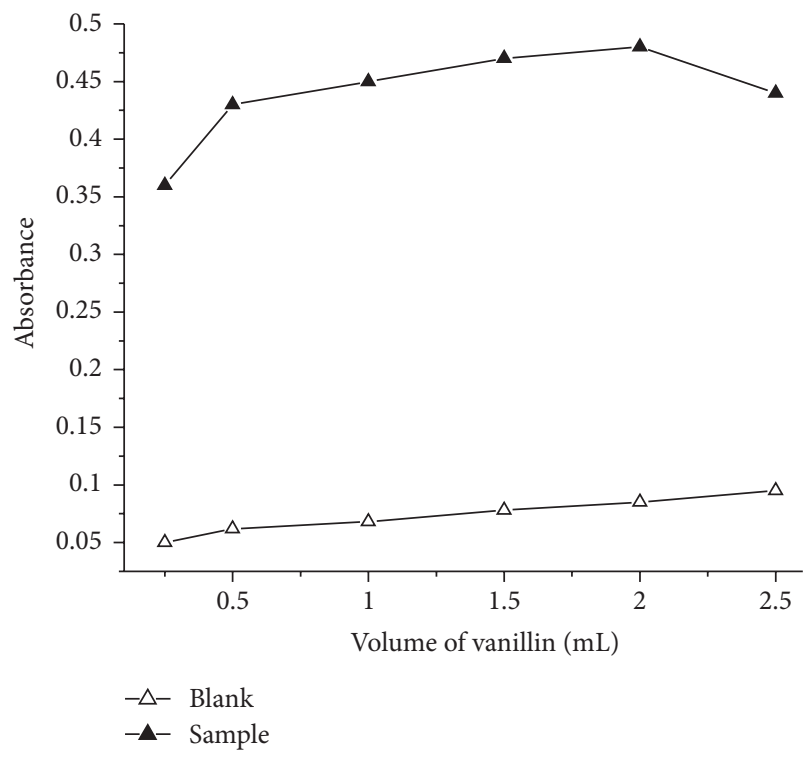

FIGURE 3: Effect of volume of $4 \%$ vanillin $\left(40 \mu \mathrm{g} \mathrm{mL}^{-1} \mathrm{ZMT}\right)$.

used, the absorbance readings were nearly constant; below and above this range there was a decrease in absorbance (Figure 3). Hence, considering minimum blank absorption and maximum chromogen absorption, $1 \mathrm{~mL}$ of $4 \%$ vanillin was used as optimum in a total volume of $10 \mathrm{~mL}$. 


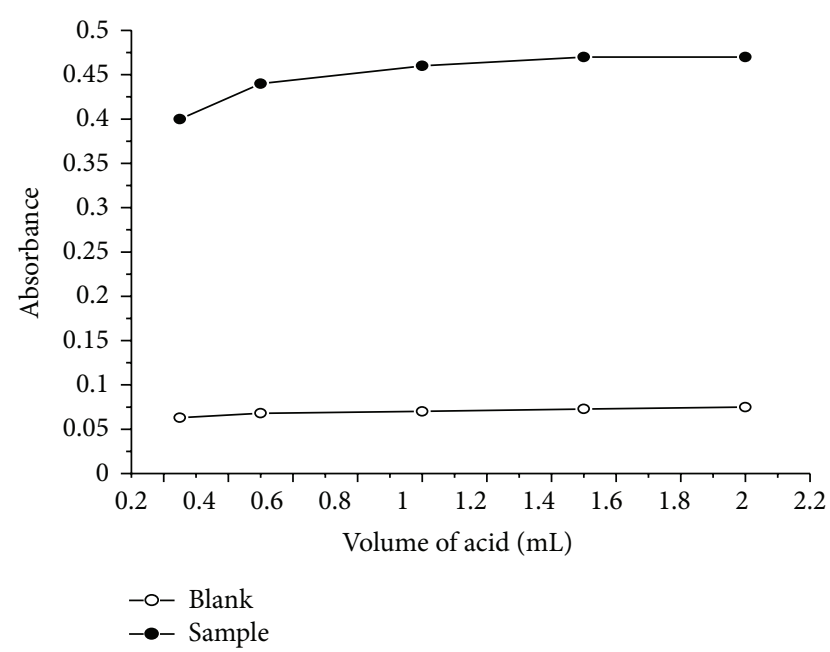

FIGURE 4: Effect of volume of conc. $\mathrm{HCl}$ solution $\left(40 \mu \mathrm{g} \mathrm{mL}^{-1} \mathrm{ZMT}\right)$.

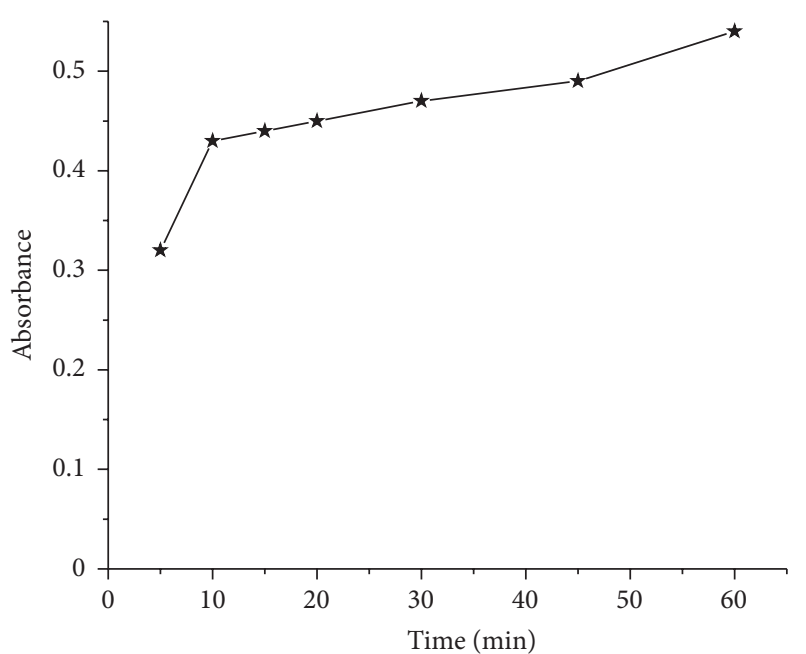

FIGURE 5: Effect of reaction time $\left(40 \mu \mathrm{g} \mathrm{mL}^{-1} \mathrm{ZMT}\right)$.

3.3.2. Effect of Acid. The reaction was very slow in dilute acidic medium; thus concentrated sulphuric acid was used. The intensity of the red-colored product was found to remain constant when $0.5-2.0 \mathrm{~mL}$ concentrated sulphuric acid was added and even no change in intensity of blank was observed (Figure 4). Hence, $1 \mathrm{~mL}$ concentrated acid in a total volume of $10 \mathrm{~mL}$ was fixed as the optimum.

3.3.3. Reaction Time. The resulting red-colored enamine was developed completely in 10 min (Figure 5) and remained stable for another $20 \mathrm{~min}$ thereafter.

\subsection{Method Validation}

3.4.1. Linearity and Sensitivity. A linear relation was found to exist between absorbance and the concentration of ZMT
TABLE 1: Regression and analytical parameters.

\begin{tabular}{lc}
\hline Parameter & Proposed method \\
\hline$\lambda_{\max }, \mathrm{nm}$ & 580 \\
Beer's law limits $\left(\mu \mathrm{g} \mathrm{mL}^{-1}\right)$ & $5.0-90.0$ \\
Molar absorptivity $\left(\mathrm{L} \mathrm{mol}^{-1} \mathrm{~cm}^{-1}\right)$ & $3.3 \times 10^{3}$ \\
Sandell sensitivity ${ }^{*}\left(\mu \mathrm{g} \mathrm{cm}^{-2}\right)$ & 0.0872 \\
Limit of detection $\left(\mu \mathrm{g} \mathrm{m}^{-1}\right)$ & 1.26 \\
Limit of quantification $\left(\mu \mathrm{g} \mathrm{mL}^{-1}\right)$ & 3.81 \\
Regression equation, $Y^{* *} \mathrm{Intercept}(a)$ & -0.0101 \\
Slope, $(b)$ & 0.0117 \\
Correlation coefficient $(r)$ & 0.9994 \\
Standard deviation of intercept $\left(S_{a}\right)$ & 0.0098 \\
Standard deviation of slope $\left(S_{b}\right)$ & 0.0002 \\
\hline
\end{tabular}

* Limit of determination as the weight in $\mu \mathrm{g}$ per $\mathrm{mL}$ of solution, which corresponds to an absorbance of $A=0.001$ measured in a cuvette of crosssectional area $1 \mathrm{~cm}^{2}$ and $l=1 \mathrm{~cm} .{ }^{* *} Y=a+b X$, where $Y$ is the absorbance, $a$ is the intercept, $b$ is the slope, and $X$ is the concentration in $\mu \mathrm{g} \mathrm{mL}^{-1}$.

in the range $5.0-90.0 \mu \mathrm{g} \mathrm{mL}^{-1}$. The calibration graph is described by:

$$
Y=a+b X
$$

where $Y$ is the absorbance, $a$ is the intercept, $b$ is the slope, and $X$ is the concentration in $\mu \mathrm{g} \mathrm{mL}^{-1}$, obtained by the method of least squares. Correlation coefficient, intercept, and slope for the calibration data are summarized in Table 1. Sensitivity parameters such as apparent molar absorptivity and Sandell sensitivity values and the limits of detection and quantification calculated as per the current ICH guidelines [27] are compiled in Table 1 and are indicative of the excellent sensitivity of the method. The limits of detection (LOD) and quantification (LOQ) were calculated according to the same guidelines using the formulae

$$
\text { LOD }=\frac{3.3 \sigma}{b}, \quad \text { LOQ }=\frac{10 \sigma}{b},
$$

where $\sigma$ is the standard deviation of five reagent blank determinations and $b$ is the slope of the calibration curve.

3.4.2. Accuracy and Precision. Accuracy was evaluated as percentage relative error between the measured concentrations and taken concentrations for ZMT (Bias \%). The results obtained are compiled in Table 2 and show that the accuracy is good. The precision of the method was calculated in terms of intermediate precision (intraday and interday). Three different concentrations of ZMT were analyzed in replicates during the same day (intra-day precision) and five consecutive days (inter-day precision). The \%RSD values of intra-day and inter-day studies showed that the precision was good (Table 2).

3.4.3. Robustness and Ruggedness. Method robustness was tested by making small incremental changes in concentrated sulphuric acid concentration and reaction time. To check the ruggedness, the analysis was performed by four different 
TABLE 2: Evaluation of intraday and interday precision and accuracy.

\begin{tabular}{|c|c|c|c|c|c|c|}
\hline \multirow{2}{*}{ ZMT taken $\left(\mu \mathrm{g} \mathrm{mL}^{-1}\right)$} & \multicolumn{3}{|c|}{ Intraday $(n=7)$} & \multicolumn{3}{|c|}{ Interday $(n=5)$} \\
\hline & ZMT found $^{\mathrm{a}}\left(\mu \mathrm{g} \mathrm{mL}^{-1}\right)$ & $\% \mathrm{RSD}^{\mathrm{b}}$ & $\% \mathrm{RE}^{\mathrm{c}}$ & ZMT found $^{\mathrm{a}}\left(\mu \mathrm{g} \mathrm{mL}^{-1}\right)$ & $\% \mathrm{RSD}^{\mathrm{b}}$ & $\% \mathrm{RE}^{\mathrm{c}}$ \\
\hline 20.0 & 19.70 & 1.45 & 1.49 & 19.68 & 1.66 & 1.61 \\
\hline 40.0 & 40.71 & 0.83 & 1.78 & 40.73 & 0.89 & 1.84 \\
\hline 60.0 & 60.61 & 1.22 & 1.02 & 60.72 & 1.55 & 1.21 \\
\hline
\end{tabular}

${ }^{\mathrm{a}}$ Mean value of five determinations; ${ }^{\mathrm{b}}$ relative standard deviation (\%); ${ }^{\mathrm{c}}$ relative error (\%).

TABLE 3: Robustness and ruggedness.

\begin{tabular}{lcccc}
\hline & \multicolumn{2}{c}{ Robustness } & \multicolumn{2}{c}{ Ruggedness } \\
ZMT taken, $\mu \mathrm{g} \mathrm{mL}^{-1}$ & $\begin{array}{c}\text { Volume of acid } \\
(n=3)\end{array}$ & $\begin{array}{c}\text { Reaction time } \\
(n=3)\end{array}$ & $\begin{array}{c}\text { Interanalysts (\%RSD), } \\
(n=4)\end{array}$ & $\begin{array}{c}\text { Interinstruments (\%RSD), } \\
(n=3)\end{array}$ \\
\hline 20.0 & 1.15 & 1.78 & 1.83 & 1.97 \\
40.0 & 1.43 & 2.19 & 1.64 & 2.13 \\
60.0 & 2.01 & 2.85 & 1.55 & 1.89 \\
\hline
\end{tabular}

The volumes of conc. $\mathrm{H}_{2} \mathrm{SO}_{4}$ solution were $0.9,1.0$, and $1.1 \mathrm{~mL}$; ${ }^{\mathrm{b}}$ reaction times were 9 , 10 , and $11 \mathrm{~min}$.

TABLE 4: Results of analysis of tablets by the proposed methods.

Tablet brand Label claim Found (percent of label claim $\pm \mathrm{SD})^{\mathrm{a}}$

name $\mathrm{mg} /$ tablet Reference method Proposed method

\begin{tabular}{|c|c|c|c|}
\hline \multirow{3}{*}{ Zomig-2.5 } & \multirow[b]{2}{*}{2.5} & \multirow{3}{*}{$100.59 \pm 0.90$} & $99.22 \pm 1.50$ \\
\hline & & & $t=1.75$ \\
\hline & & & $F=2.77$ \\
\hline
\end{tabular}

a Mean value of five determinations.

Tabulated $t$-value at the $95 \%$ confidence level is 2.78 .

Tabulated $F$-value at the $95 \%$ confidence level is 6.39 .

analysts and on three different instruments by the same analyst. The robustness and the ruggedness were checked at three different drug levels. The intermediate precision, expressed as \%RSD, which is a measure of robustness and ruggedness was within the acceptable limits as shown in the Table 3.

3.4.4. Selectivity. The selectivity of the proposed method for the analysis of ZMT was evaluated by placebo blank and synthetic mixture analyses. The recommended procedure was applied to the analysis of placebo blank, and the resulting absorbance readings were the same as that of the reagent blank, confirming no interference from the placebo.

The analysis of synthetic mixture solution yielded percent recoveries, which ranged between 98.38 and 101.7 with standard deviation of 1.06-1.93. The results of this study show that there is no interference from the commonly added excipients in pharmaceutical formulations and confirmed the selectivity of the method.

3.4.5. Application to the Analysis Tablets. In order to evaluate the analytical applicability of the proposed method to the quantification of ZMT in commercial tablets, the results obtained by the proposed method were compared to those of the reference method [10] by applying Student's $t$-test for accuracy and $F$-test for precision. The reference method describes chromatographic separation of ZMT with UVdetection at $225 \mathrm{~nm}$. The results (Table 4) show that the Student's $t$ - and $F$-values at 95\% confidence level are less than the theoretical values, indicating that there is a good agreement between the results obtained by the proposed method and the reference method with respect to accuracy and precision.

3.4.6. Recovery Studies. The accuracy and validity of the proposed method were further ascertained by performing recovery studies. Preanalyzed tablet powder was spiked with pure ZMT at three levels $(50,100$, and $150 \%$ of that found in tablet powder), and the total was determined by the proposed method. The percent recovery of pure ZMT added was in the range of $101.4-102.3 \%$ with standard deviation of $0.82-$ 1.45 (Table 5), indicating that the recovery was good and that the coformulated substance did not interfere in the determination.

\section{Conclusions}

The proposed method is selective as aromatic secondary amino group present in ZMT selectively condensed with the aromatic aldehyde group present in the vanillin. One of the previously reported methods requires expensive reagent [22], and the other two methods [23] involve extraction step and strict $\mathrm{pH}$ control and require large quantity of organic solvents. In contrast, the present method is free from rigid experimental conditions and is characterized by simplicity, reasonable sensitivity, cost-effectiveness, and use of easily available chemicals when compared to the existing spectrophotometric methods. Selectivity of the reaction is reflected in satisfactory recovery of ZMT in the presence of excipients in pharmaceuticals. The reaction is rapid compared to previously reported extractive spectrophotometric methods. The method can be useful in the quality control of bulk drug and tablet dosage form. 
TABLE 5: Results of recovery study by standard addition method.

\begin{tabular}{lcccc}
\hline Tablets studied & ZMT in tablets, $\mu \mathrm{g} \mathrm{mL}^{-1}$ & Pure ZMT added, $\mu \mathrm{g} \mathrm{mL}^{-1}$ & Total found, $\mu \mathrm{g} \mathrm{mL}{ }^{-1}$ & Pure ZMT recovered* ${ }^{*}$ percent \pm SD \\
\hline \multirow{2}{*}{ Zomig-2.5 } & 19.84 & 10.0 & 30.01 & $101.7 \pm 0.82$ \\
& 19.84 & 20.0 & 40.13 & $101.4 \pm 1.12$ \\
& 19.84 & 30.0 & 50.52 & $102.3 \pm 1.45$ \\
\hline
\end{tabular}

Mean value of three determinations.

\section{Acknowledgments}

The authors wish to acknowledge Cipla India Ltd., Mumbai, India, for providing the gift sample of zolmitriptan. One of the authors (Kudige N. Prashanth) also wishes to thank the authorities of the University of Mysore for giving permission and facilities to carry out the research work. The authors do not have any conflict of interests with the commercial identities mentioned in the paper.

\section{References}

[1] B. Kilic, T. Ozden, S. Toptan, and S. Ozilhan, "Simultaneous LCMS-MS determination of zolmitriptan and its active metabolite $\mathrm{N}$-desmethylzolmitriptan in human plasma," Chromatographia, vol. 66, pp. S129-S133, 2007.

[2] E. M. Clement and M. Franklin, "Simultaneous measurement of zolmitriptan and its major metabolites $N$-desmethylzolmitriptan and zolmitriptan $N$-oxide in human plasma by highperformance liquid chromatography with coulometric detection," Journal of Chromatography B, vol. 766, no. 2, pp. 339-343, 2002.

[3] J. Yao, Y. Qu, X. Zhao et al., "Determination of zolmitriptan in human plasma by high performance liquid chromatographyelectrospray mass spectrometry and study on its pharmacokinetics," Journal of Chinese Pharmaceutical Sciences, vol. 14, no. 1, pp. 25-28, 2005.

[4] Z. Zhang, F. Xu, Y. Tian, W. Li, and G. Mao, "Quantification of zolmitriptan in plasma by high-performance liquid chromatography-electrospray ionization mass spectrometry," Journal of Chromatography B, vol. 813, no. 1-2, pp. 227-233, 2004.

[5] D. Wang, D. S. Ouyang, Z. R. Tan et al., "HPLC-MS determination of zolmitriptan in human plasma and research of its bioequivalence," Chinese Journal of Pharmaceutical Analysis, vol. 27, no. 2, pp. 171-173, 2007.

[6] H. H. Zhou, X. J. Peng, Z. R. Tan, D. S. Ouyang, L. J. Liu, and L. L. Dai, "LC-MS/MS determination of zolmitriptan and its active metabolite $\mathrm{N}$-desmethyl-zolmitriptan in human plasma," Chinese Journal of Pharmaceutical Analysis, vol. 30, no. 8, pp. 1407-1411, 2010.

[7] X. Chen, D. Liu, Y. Luan, F. Jin, and D. Zhong, "Determination of zolmitriptan in human plasma by liquid chromatographytandem mass spectrometry method: application to a pharmacokinetic study," Journal of Chromatography B, vol. 832, no. 1, pp. 30-35, 2006.

[8] E. K. S. Vijayakumar, M. A. Samel, S. B. Bhalekar, and S. M. Pakhale, "A new stability indicating HPLC method for related substances in zolmitriptan," Indian Journal of Pharmaceutical Sciences, vol. 72, no. 1, pp. 119-122, 2010.

[9] M. M. Annapurna and B. Nanda, "Validated RP method for the determination of zolmitriptan-a serotonin 5-HT receptor agonist," Journal of Pharmacy and Nutrition Sciences, vol. 1, no. 1, pp. 9-14, 2011.
[10] D. G. Sankar, A. Nagesh Babu, A. Rajeshwari, and M. Vamsi Krishna, "Development and validation of RP-HPLC method for estimation of zolmitriptan in tablet dosage forms," Asian Journal of Chemistry, vol. 21, no. 7, pp. 5019-5022, 2009.

[11] M. K. Srinivasu, B. M. Rao, G. Sridhar, P. R. Kumar, K. B. Chandrasekhar, and A. Islam, "A validated chiral LC method for the determination of Zolmitriptan and its potential impurities," Journal of Pharmaceutical and Biomedical Analysis, vol. 37, no. 3, pp. 453-460, 2005.

[12] P. V. Sagar, D. Kumar, S. Dey, and H. B. Samal, "Simultaneous estimation of rizatriptan, sumatriptan and zolmitriptan by RPHPLC method in bulk," Journal of Pharmacy Research, vol. 3, no. 12, pp. 2930-2933, 2010.

[13] M. Induri, R. M. Bhagavan, P. Y. Rajendra, R. K. Pavankumar, R. Boddu, and R. Sarva, "A validated RP-HPLC method for the quantification of zolmitriptan in tablet dosage form," Der Pharma Chemica, vol. 2, no. 5, pp. 351-357, 2010.

[14] D. Rambabu, B. Bhoomaiah, R. S. C. Phani, and K. B. Krishna, "Validated RP-HPLC method for the estimation of Zolmitriptan in formulation," Pharmacophore, vol. 2, no. 2, pp. 150-155, 2011.

[15] N. U. Rani, R. S. Rao, K. Saraswathi, and T. E. G. K. Murthy, "Development and validation of LC method for the estimation of Zolmitriptan in pharmaceutical dosage form," Pharmacophore, vol. 2, no. 3, pp. 195-200, 2011.

[16] Y. K. Reddy, G. V. S. Reddy, and K. N. Jayaveera, "A new stability indicating RP-UPLC method for related substances in zolmitriptan," African Journal of Scientific Research, vol. 1, no. 1, pp. 50-62, 2011.

[17] B. M. Rao, M. K. Srinivasu, G. Sridhar, P. R. Kumar, K. B. Chandrasekhar, and A. Islam, "A stability indicating LC method for zolmitriptan," Journal of Pharmaceutical and Biomedical Analysis, vol. 39, no. 3-4, pp. 503-509, 2005.

[18] B. Uslu and D. Canbaz, "Anodic voltammetry of zolmitriptan at boron-doped diamond electrode and its analytical applications," Pharmazie, vol. 65, no. 4, pp. 245-250, 2010.

[19] S. K. Acharjya, M. E. B. Rao, B. V. V. R. Kumar, and M. M. Annapurna, "UV-spectrophotometric methods for the determination of zolmitriptan in bulk and pharmaceutical dosage forms," Journal of Advanced Scientific Research, vol. 2, no. 3, pp. 42-47, 2011.

[20] T. E. G. K. Murthy and K. Veditha, "Spectrophotometric estimation of zolmitriptan," Indian Pharmacist, vol. 9, no. 12, pp. 57-60, 2011.

[21] D. G. Sankar, A. N. Babu, A. Rajeswari, M. V. Krishna, and K. V. Devi, "Spectrophotometric determination of zolmitriptan in pharmaceutical dosage forms," Asian Journal of Chemistry, vol. 20, no. 6, pp. 4960-4962, 2008.

[22] A. Raza, T. M. Ansari, and S. B. Niazi, "A novel spectrophotometric method for the determination of zolmitriptan in pharmaceutical formulations," Journal of the Chinese Chemical Society, vol. 54, no. 6, pp. 1413-1417, 2007. 
[23] Z. Aydogmus and I. Inanli, "Extractive spectrophotometric methods for determination of zolmitriptan in tablets," Journal of AOAC International, vol. 90, no. 5, pp. 1237-1241, 2007.

[24] B. L. Joseph and R. B. Wallace, "Condensations of secondary amines with aldehydes and naphthols," Journal of American Chemical Society, vol. 52, no. 4, pp. 1655-1659, 1930.

[25] M. A. Youngman and S. L. Dax, "Solidphase Mannich condensation of amines, aldehydes, and alkynes: investigation of diverse aldehyde inputs," Journal of Combinatorial Chemistry, vol. 3, no. 5, pp. 469-472, 2001.

[26] O. Z. Devi, K. Basavaiah, K. B. Vinay, and H. D. Revanasiddappa, "Sensitive spectrophotometric determination of metoclopramide hydrochloride in dosage forms and spiked human urine using vanillin," Arabian Journal of Chemistry, 2011.

[27] "Validation of analytical procedures: text and methodology," in Proceedings of the International Conference on Harmonization of Technical Requirements Registration of Pharmaceuticals for Human Use, ICH Harmonized Guideline, Q2 (R1), complementary guideline on methodology, London, UK, November 1996. 

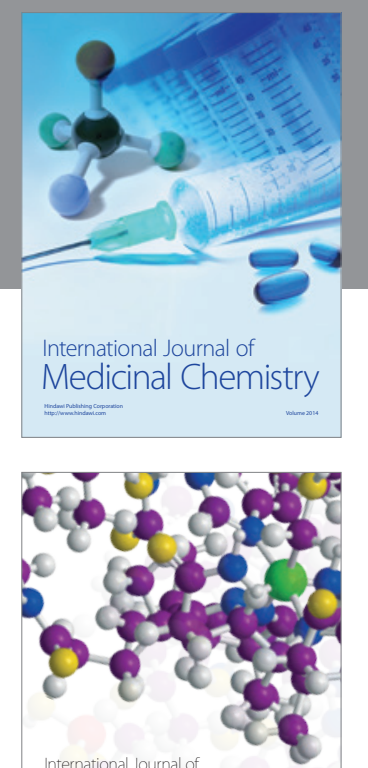

\section{Carbohydrate} Chemistry

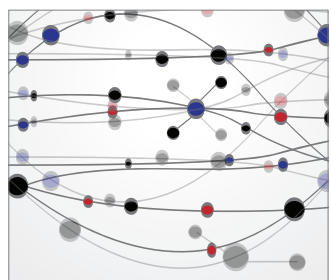

The Scientific World Journal
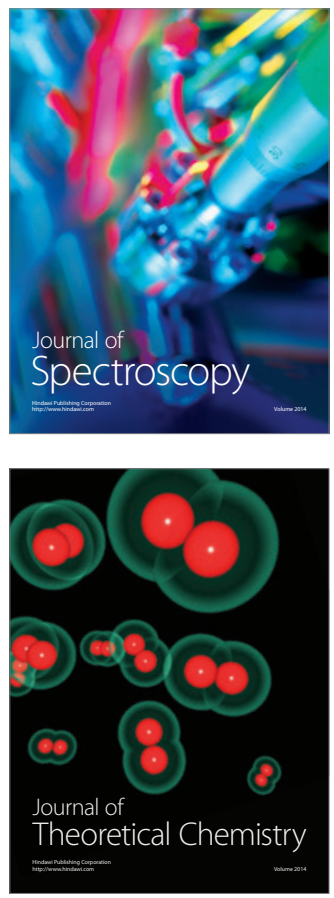
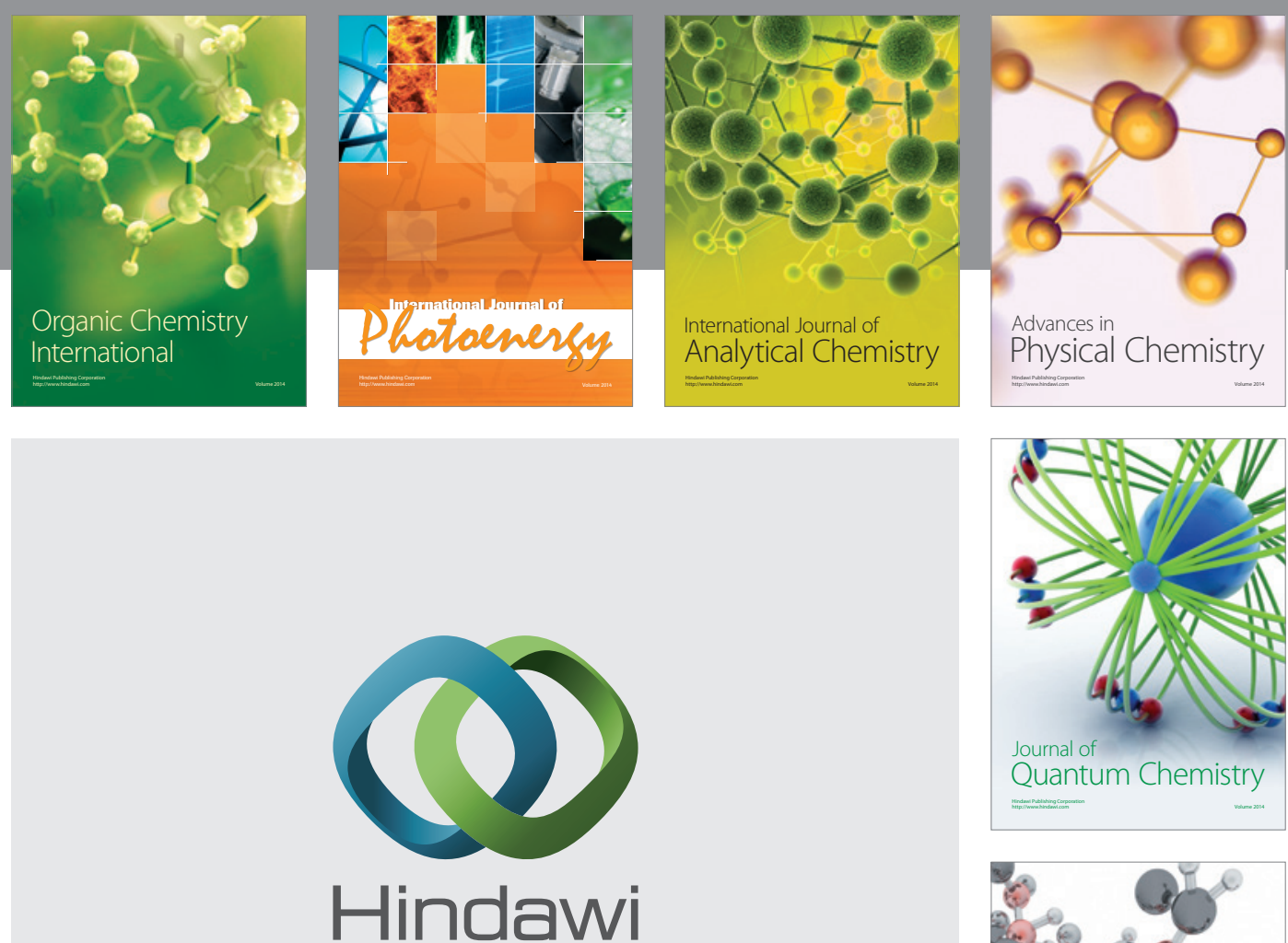

Submit your manuscripts at

http://www.hindawi.com

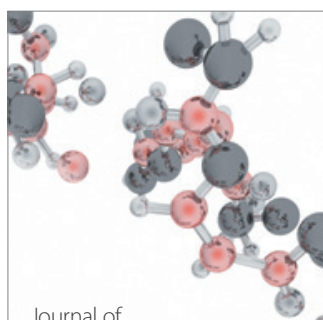

Analytical Methods

in Chemistry

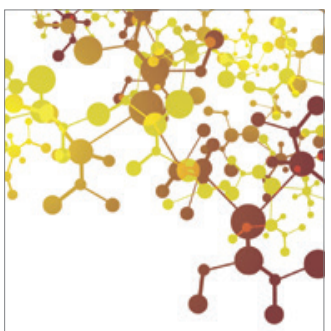

Journal of

Applied Chemistry

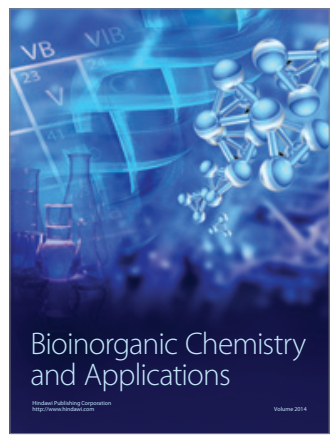

Inorganic Chemistry
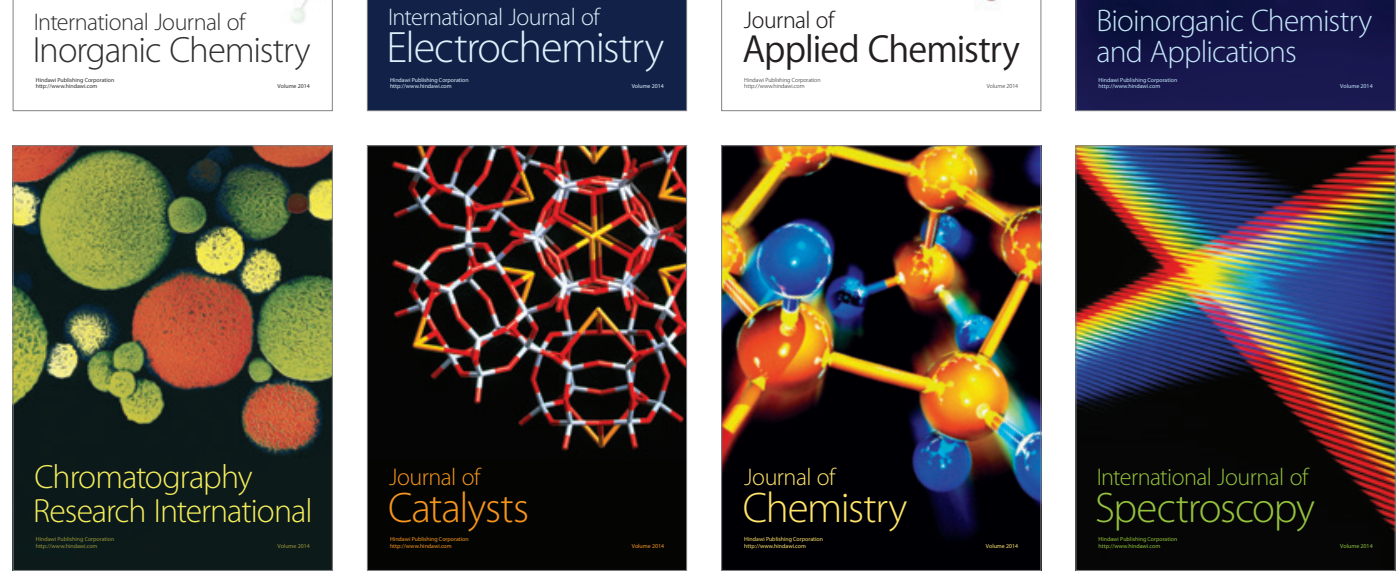